\title{
A new innovation paradigm: combining technological and social innovation
}

\author{
Michael Kohlgrüber ${ }^{1}$, Antonius Schröder ${ }^{1,}$, Félix Bayón Yusta ${ }^{2}$, and Asier Arteaga Ayarza ${ }^{2}$ \\ 1 Technische Universität Dortmund-Social Research Centre sfs, Dortmund, Germany \\ ${ }^{2}$ Sidenor Aceros Especiales S.L, Bilbao, Spain
}

Received: 15 June 2018 / Accepted: 7 December 2018

\begin{abstract}
A new innovation paradigm is needed to answer the societal, economic and environmental challenges the world and companies are facing. The EU funded Horizon 2020 SPIRE Project "Coordinating Optimisation of Complex Industrial Processes" (COCOP) is combining technological and social innovation within a steel company pilot case (Sidenor). The project aims at reducing raw materials consumption (and energy and emissions reduction as well) by plant-wide optimisation of production processes based on a software solution and at the same time changing social practices. Key for COCOP is a methodology integrating technological innovation within a social innovation process of co-creation and co-development by involving (potential) users of the future software system and relevant stakeholders right from the beginning; thereby improving effectiveness and impact of the innovations and the implementation process. This involvement is instructed and measured by social key performance indicators (social KPIs) and operationalised in surveys (questionnaire and interviews) with future users, engineers and external experts (from different industry sectors not involved in the project). The article presents the results of the starting point of COCOP illustrating the future user perspective of the pilot steel company (Sidenor) contrasted by the view of external experts - seriously taking into account the interfaces between technology, human and organisation.
\end{abstract}

Keywords: social innovation / plant-wide optimisation / co-creation / human factor requirements

Résumé. Un nouveau paradigme d'innovation : combiner innovation technologique et innovation sociale. Un nouveau paradigme d'innovation est nécessaire pour répondre aux défis sociétaux, économiques et environnementaux auxquels le monde et les entreprises sont confrontés. Le projet « coordonner l'optimisation de processus industriels complexes» (COCOP), financé par l'UE Horizon 2020 SPIRE, combine innovation technologique et sociale dans le cadre d'un projet pilote d'une entreprise sidérurgique (Sidenor). Le projet vise à réduire la consommation de matières premières (et aussi l'énergie et les émissions) en optimisant les processus de production à l'échelle de l'entreprise, à l'aide d'une solution logicielle, tout en modifiant les pratiques sociales. La clé pour COCOP est une méthodologie qui intègre l'innovation technologique dans un processus d'innovation sociale de co-création et de co-développement en impliquant les utilisateurs (potentiels) du futur logiciel et les parties prenantes concernées au début; cela améliore l'efficacité et l'impact des innovations et du processus de mise en œuvre. Cette implication est identifiée et mesurée par des indicateurs de performance sociale (KPI) et opérationnalisée par des enquêtes (questionnaire et entretiens) avec des futurs utilisateurs, ingénieurs et experts externes (de différents secteurs industriels non impliqués dans le projet). L'article présente les résultats du point de départ du COCOP, qui présente le point de vue des utilisateurs futurs de l'entreprise sidérurgique (Sidenor) par rapport à l'opinion d'experts externes, en prenant au sérieux les interfaces entre technologie, personnel et organisation.

Mots clés : innovation sociale / optimisation à l'échelle de l'usine / co-création / besoins en facteurs humains

\footnotetext{
* e-mail: schroeder@sfs-dortmund.de
} 


\section{Introduction}

The starting point for combining technological development with the concept of social innovation is that there is a lot of technological innovation without societal and market-related relevance. The impact of this missing link between technological innovation and societal, economic and environmental innovation is experienced by many frustrated software developers working on technological solutions, which are not implemented in practice. Therefore, this article is pleading for the integration of technological development within a social innovation process, stating that:

- every technological innovation is also a social innovation (process), which is decisive or at least co-determining for efficiency and effectiveness, success and failure of an innovation;

- technology has to be seen as an enabler of innovation (referring to "A New Nature of Innovation" $[1,2]$ ) and not as a subject as such (developing technology solutions because they are technological possible without a clear link to societal, economic and environmental challenges and implementation).

Furthermore, this means that an innovation approach has to be considered, overcoming the limits of pure technological oriented developments and embedding technology in social innovation processes. This new innovation perspective (leading to a new innovation paradigm, described in Sect. 2) has already been reflected since the start of the Horizon 2020 programme of the European Commission [3]. Herein, non-technological and social innovation are explicitly mentioned as relevant aspects of research and innovation within Horizon 2020 [4].

Within the European public-private partnership SPIRE (Sustainable Process Industry through Resource and Energy Efficiency) and its funded COCOP project (Coordinating Optimisation of Complex Industrial Processes) ${ }^{1}$, this approach is tested by setting up a social innovation concept and process (innovation process design): considering co-creation [5], (economic, social, environmental) impact as well as organisational and personnel development right from the beginning by a consequent stakeholder and user involvement.

SPIRE and therefore COCOP as well aim at [6]:

- industry cross-sectoral technological solution to reduce fossil energy (e.g. through novel energy-saving processes, process intensification, energy recovery, sustainable water management, co-generation heat-power and progressive introduction of alternative (renewable) energy sources within the process cycle);

- decreasing the use of non-renewable, primary raw material intensity (e.g. by increasing chemical and physical transformation yields and/or using secondary and renewable raw materials);

\footnotetext{
${ }^{1}$ The COCOP project has received funding from the European Union's Horizon 2020 research and innovation programme under grant agreement No. 723661.
}

- a significant contribution to the political and societal objectives of drastic efficiency improvement in $\mathrm{CO}_{2^{-}}$ equivalent.

Facing societal, economic and environmental challenges, companies in the process industry require to raise their production processes to the next level by facing critical environmental challenges, such as reducing pollution and a more efficient use of resources (raw material, energy). To strengthen competitiveness of European process industries, companies have to reduce operating costs through better process control. To improve working conditions, secure and promote employment and to provide companies with needed skills, social issues have to be taken into account when innovation is taking place in these industries.

Traditional approaches focus mainly on optimisation of sub-processes in process industries: targets refer to the performance of a sub-process; operators and managers are responsible for their production area, respectively installation, knowledge and experiences focus on the owned subprocess. Even if optimisation has to consider influences of previous sub-processes and effects on following subprocesses, the effects on relevant parameters of the production process as a whole (e.g. the quality of the final product) are not fully considered. Digitisation (e.g. big data, Industry 4.0) has the potential to understand and improve the relationships between the parameters of subprocesses and the results of the whole production process. However, plant-wide optimisation is also a social phenomenon. It requires another mind-set of operators and managers to take responsibility for the whole process instead of an optimisation of a limited production area. This needs closer collaboration and communication between the persons in charge for the different processes, but also a better understanding of the whole production process. Additional skills need to become part of training for operators and managers to gain deeper insights in interrelationships between the different sub-processes. Target and bonus systems have to be adapted to the new objectives: instead of rewarding good results within the owned sub-process, the contribution to the performance of plant-wide processes should be focused. That is what is basically meant by the term "social innovation" [7] in this context: changing (social) practices, such as working practices and organisational practices. Some of them are reflected in social key performance indicators (e.g. "Better understanding of plant-wide processes", "Needed skills" described in Sect. 4), some are covered by the human factors requirements (see "New communication channels" or "Bonus systems" in Sect. 5).

Within the EU funded Horizon 2020, SPIRE Project COCOP (www.cocop-spire.eu), a new approach, is being developed that aims at such a plant-wide optimisation. Since this challenge is too complex for a human without computing tools, COCOP is developing a software solution that will support the operator making decisions and benefits the overall plant efficiency.

However, a more comprehensive innovation approach is needed to meet the requirements of societal, economic and environmental challenges mentioned above. More and 
more, social innovation is moving into the focus of practitioners and scientists to meet these challenges $[8,9]$. For example, the EU funded project SI-DRIVE has developed an "Atlas of Social Innovation" (www.social innovationatlas.net) [10] mapping social innovations all over the world, covering different policy fields (such as energy supply and climate change), practice fields and sectors of innovation in order to meet societal and social challenges. The project EU Research Fund for Coal and Steel funded "Robotic workstation in harsh environmental conditions to improve safety in the steel industry" (ROBOHARSH) deals explicitly with a new innovation paradigm that stresses the interaction of social and technological innovation in the steel industry [11] to advance the allocation of the particular capabilities of human and technology and to improve the production processes.

COCOP valorises this approach by aiming at the best possible interplay of human and technology to reach plantwide optimisation. "Social innovation focuses on changing social practices to overcome societal challenges, meeting social demands and exploiting inherent opportunities in better ways than done before. It represents an understanding of innovation that goes beyond pure technological and/ or business innovation" [12]. For COCOP, this means that human factors issues are considered right from the beginning. Consequently, not only impact on social and societal issues is regarded. In fact, a strong participation of future end users and other stakeholders is taking place to make them co-creators for a new solution for a plant-wide optimisation. Beyond earlier works on social innovation, COCOP is more positioned in the application end, involving that:

- mutual learning of technical designers and human factors experts is needed;

- real interaction between the different disciplines has to take place;

- common work of both parties (engineers and human factor experts) is needed to get to solutions that will work;

- a common language, common templates, common timelines, etc. have to be defined to which both parties contribute.

Against this backdrop, the article is describing the contours of a new innovation paradigm and its implementation, exemplarily shown by the development of a plant-wide optimisation system in the steel industry (within the COCOP project and the Spanish steel company Sidenor). The paradigm change from pure software development to codesigning of new working practices is underlined by first findings of empirical research (questionnaires and interviews of the future users) showing the human requirements at the beginning of the innovation process and its consequences for the further technological development process.

\section{A new innovation paradigm}

The term of innovation is subject to a long history of change in understanding, enclosing more general connotations of creating something new, changing societies or linked to economic value creation and technological developments [13]. The scientific discipline of innovation studies (see e.g. [14-18]) has started with the first industrial revolution at the end of the 18th century (with water and steam powered manufacturing) up to the now so-called fourth industrial revolution based on new cyber-physical systems $^{2}$. A major milestone in innovation studies still influencing common understanding of innovation is Schumpeter's 1912 publication of "Theorie der wirtschaftlichen Entwicklung" (Theory of economic development) [20]. Schumpeter, a political economist, shaped the perspective on innovation with an economically rooted conception. Its main elements included an understanding of innovation as new combinations of production factors, such as the introduction of new products, production methods, using new materials, etc. [21]. Linked to the success of innovation in changing economic systems is the distribution of innovation. Hence, Schumpeter defined diffusion as the third phase of the innovation process making it an imperative element without an invention cannot become a successful innovation. Because of its capacity, this theory is still a crucial building block for understanding the process, stages and elements of innovation. Schumpeter's work represents a broad understanding of innovation that did not only focus on technological innovation but also included non-technological innovation, such as organisational innovation. Whereas Schumpeter created a milestone in innovation studies, his work should not be mixed up with the starting point for a shift towards understanding innovation as technological innovation. Godin [13,22] demonstrates that the success story of the technological aspect in innovation studies dates back to other scientists with a stronger connection to research on technology like Maclaurin [23] (an economic historian related to the MIT) and, more generally, "policy-makers, natural scientists and science and technology theorists" [13]. In addition to the influence of innovation studies, the understanding on (technological) innovation was also shaped by practitioners, most prominently engineers. Hence, understanding of innovation as technological innovation was influenced by two parallel discourses, a scientific and a more practically oriented one [13]. Nowadays, the influence of Schumpeter and the focus on value creation together with the focus on technology are still predominant in an applied understanding of innovation as shown in literature [24].

But things have changed when companies and policymakers started realising upcoming societal and environmental challenges (such as climate change or inclusive growth) and other perspectives are emerging and reemerging. So, the historical perspective shows a development from a technology focused angle to a "process of system innovation (embodying invention, innovation and diffusion) [...involving] multiple actors in negotiating alternative pathways that have the potential to achieve system change." [25]. For finding new, hence innovative, pathways to tackle the variety of challenges, needs and demands, the perspective on innovation had to be

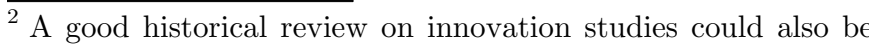
found at Bijker et al. [19].
} 
expanded. Policy-makers increasingly realise the importance of different approaches to innovation taking the human factor and the impact on societies as well as the potential of a larger variety of innovation for societies into account.

This is reflected by three settings of innovation policy Schot and Steinmüller [25] showed for different time periods after the Second World War:

- in the first setting policy makers supported innovation for economic growth to secure employment and prosperity;

- National Innovation Systems as configurations of organisations concerned with the generation of technological knowledge [26-28] were the answer of national innovation policy to an increasing global competition;

- policy makers supported a transformative change aligning innovation with societal challenges such as energy reduction and pollution, e.g. in the EU H2020 programme.

This latest evolution of innovation policy unveils the broadening of understanding innovation as it is taking into account the potential for transformation beyond economic growth. When innovation is seen to have potential for coping with societal challenges, needs and demands [29], it can be described as "social innovation". In the sense of Howaldt and Schwarz [7], social innovation is focusing on the renewal of social practices ${ }^{3}$ or configurations of practices of any kind, diffused into society and without a limitation to a need for creating social value. Social innovation can therefore also explain the emergence of new practices in industry and towards sociotechnical systems (such as new working practices based on new skills needed by digital technologies and organisational changes).

In practice, this evolution from a technology focus to an independent approach of social innovation can be understood by considering some major stages of innovation in industry. Particularly in the 1980s, engineers were guided by the vision of an unmanned operation of manufacturing plants [30]. Concepts such as Computer Integrated Manufacturing (CIM) are witnesses of these ambitions, but its implementation in production plants (e.g. "Halle 54 ", a plant of the Volkswagen car company in Germany) showed the dysfunctionalities and contradictions of these technology-centred approaches [31]. However, there were already approaches in the decades before and after CIM that stressed the necessity of integrating technological and non-technological issues: the concept of sociotechnical systems was developed in the 1950s stressing the interaction of technology, skills and organisation as drivers for successful innovation [32]. Lutz [33] stated a consensus in industrial sociology on "the end of technological determinism". Consequently, an "understanding of innovation in which technological and social innovation are mutually dependent" would be more appropriate [31]. However, the effect on practical change was slow and technology remained dominant in the practice of companies. Meanwhile, awareness for the necessity for a broader understanding of innovation including technological and social

\footnotetext{
3 "Social practices" in this sense aims at interaction practices of people.
}

innovation has increased [34], because companies are facing a broad range of challenges including economic, societal and environmental issues. However, social innovation is often understood as a contrast or a competitor to technological innovation. Bolwijn et al. [35] stated already in 1986 that social innovation might be more important than technological innovation. Howaldt et al. [31] call upon rare success of technology-driven innovation and emphasise to "focus on social innovations instead of technology". Gardner et al. [36] found "disparate schools of thought" to develop innovations for global health: on the one hand preferring technological solutions, on the other hand stressing systemic solutions based on organising human resources. However, to play technological and social innovation against each other prevents fully benefit from both. Therefore, awareness is rising that a combination of both unfolds the full potential of technological and social innovation. Green et al. [37] are laying "less emphasis upon technology, rather a combination of technological, social and cultural changes is envisaged". The approach of "Workplace Innovation" [34] accentuates technological and non-technological innovation as complementary and mutually integrated. According to this approach, it is particularly about workers' engagement and employee driven innovation to make best use of new technologies within an appropriate work organisation at the workplace.

Having said this, today's understanding of social innovation is quite different. Some authors are stressing a social purpose of this kind of innovation, such as tackling poverty, climate change or improving education and health delivering social value [38]. Other authors [24,39] define social innovation as reconfiguration of social practices, which may not necessarily have a social purpose. Brooks [40] made a distinction between technical, sociotechnical and social innovations. According to this approach, management innovation is also understood as social innovation ${ }^{4}$. Based on such a non-normative approach, "Lean Production" mainly discussed and implemented in the 1990s can be seen as management innovation and - according to Brooks [40] - as social innovation because of its focus on organisational rather than technological innovation. Teamwork, Kaizen, Kanban and other elements of Lean Production do not require high tech solutions [42]-they mainly benefit from organisational solutions. Open innovation is also a concept of "a distributed innovation process based on purposively managed knowledge flows across organisational boundaries, using pecuniary and non-pecuniary mechanisms in line with the organisation's business model" ([43], see also $[44,45])$. In the current innovation debate, this can be received as social innovation [24,39], if it is understood as new or reconfigured social practices (including working practices, organisational practices, etc.), i.e. people are performing their tasks somewhat differently: they might be using new technologies, new skills and/or new organisational solutions [46].

\footnotetext{
${ }^{4}$ On overview of management innovation in relation to social innovation could be found at Dhondt and Oeij [41].
} 


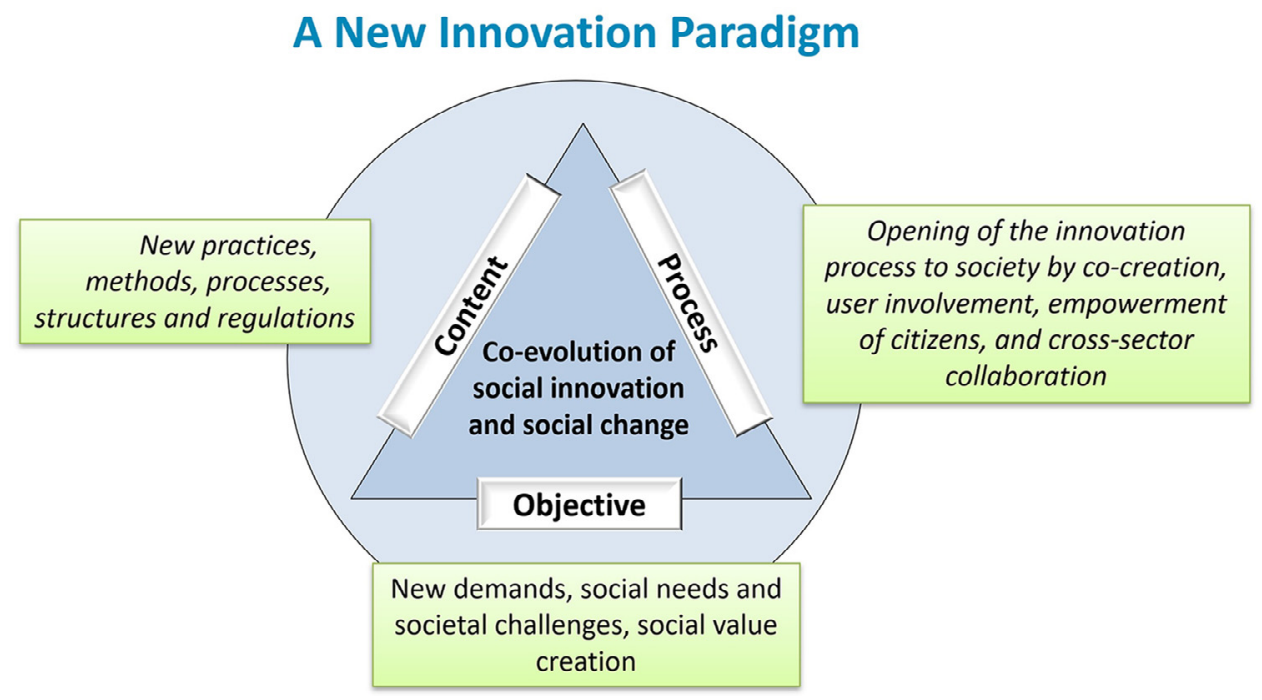

Fig. 1. New innovation paradigm.

Fig. 1. Nouveau paradigme d'innovation.

The current wave of innovation, often called "Industry 4.0" or the Fourth Industrial Revolution [47], is mainly based on (digital) technology, but built on the principles of Lean Production as well. Against this backdrop, there is, to some extent, already a combined approach of technological and social innovation. Having said this, to unfold the full potential of this approach, the interaction of the different areas of innovation has to be shaped consciously to address the current economic, societal and environmental challenges. Following Howaldt and Schwarz [39], we have to change our perspective from a focus on technological artefacts and their social conditions to new social practices to solve societal challenges of any kind, where technology can but not must play a role.

That is, what is meant by this proposed "new innovation paradigm" [11,31] (see Fig. 1).

The new innovation paradigm is based on three pillars: - its subject is new practices that include new technologies, but go beyond by including skills and organisational changes;

- its objectives go beyond technical efficiency, they include also social and environmental objectives and address thereby current societal challenges;

- the social innovation process fosters co-creation of stakeholders and end users of a new (technological) solution by participating within the development process.

In short: a combined technological and social innovation approach perceiving stakeholders and end users not only as feedback providers but also as co-creators lead to a holistic sociotechnical system that benefits from the adjusted interaction of technology, human resources and organisation. Hirsch-Kreinsen $[48,49]$ stresses that particularly the interfaces between these elements of a sociotechnical system have to be taken into account (see Fig. 2).

For the current wave of digitisation, this has already been discussed in literature to a lesser or greater extent (e.g. $[11,49])$. The discussion reflects a huge advance over the time when discussion on technological innovations (such as Computer Integrated Manufacturing in the 1980s) took place (e.g. $[50,51])$. While in the 1980 s, the unmanned factory was a guiding principle for technology development, the sociotechnical system approach is nowadays widely recognised in current research and development projects on digitisation (e.g. [52]). Different disciplines (engineers, software developers, social scientists, training specialists, industrial psychologist) seem to agree about central principles of shaping new technology in the context of sociotechnical systems [53]. Nonetheless, the problem of different "languages" and "cultures" (between technological and non-technological disciplines) has to be tackled to achieve integrated solutions [36]. Based on current results of the COCOP project, this paper describes a process that brings the "new innovation paradigm" closer to application, showing a process that includes the identification of current production processes, involved key staff, key performance indicators, user requirements and influences on the software development process. Exemplarily, this process takes place at Sidenor, a steel company in the Basque country that serves as pilot case for the COCOP project. The following chapter describes the needs of this steel company related to the plant-wide optimisation approach realised in COCOP.

\section{Plant-wide optimisation approach in the steel industry (the Sidenor case)}

\subsection{The general COCOP approach}

The process industries are facing multiple (economic, social and environmental) challenges and constraints - improving efficiency and quality as well as reducing costs to improve competitiveness, reducing raw materials consumption and energy usage to handle limited resources, reducing pollution to contribute to a healthy environment, maintaining/creating jobs for prosper regions and providing 


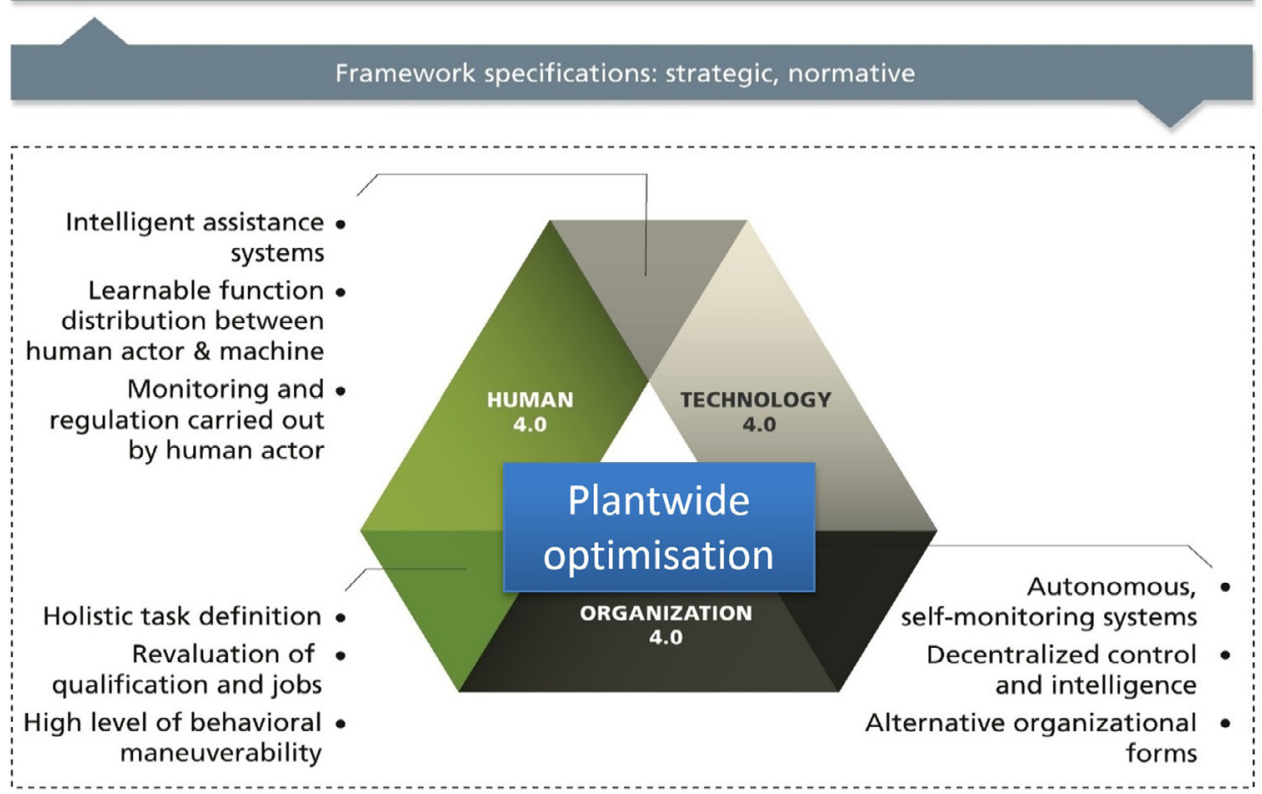

Fig. 2. The sociotechnical system (source: [49]).

Fig. 2. Le système socio-technique (source: [49]).

healthy, learning and personality enhancing working conditions. Optimisation of production processes in these industries, in the sense of COCOP, means balancing contradicting goals to contribute to a circular economy. Traditional approaches focused on optimisation of subprocesses - targets of managers are related to sub-processes, bonus systems supported sub-process optimisation, experience of efficient operation is focused on the limited area of responsibility, operator's attention is focused on everyday problems and departments are inclined to prioritise their knowledge about owned sub-processes. In contrast to this, COCOP aims at plant-wide optimisation to reach an overall plant efficiency. However, it is a considerable challenge to optimise complex processes of process industries (e.g. steel, copper or chemical industry being part of the COCOP project). Different unit processes and side streams have to be managed. In these industries, maximum efficiency operating processes have to deal with different capacities of the involved installations and with changing bottlenecks during operation. Therefore, making trade-offs between capacity, yield, energy efficiency, process wear, etc. has to change as well [54].

Due to the complex nature of the considered industrial processes, a scientific decomposition-coordination approach is being applied. This means that a large, plantwide master problem is being decomposed in several subproblems. COCOP defines the relevant parameters to coordinate solutions for sub-problems to solve the master problem: "Based on mathematical modelling of complex processes and decomposing the models to solvable subproblems and coordinating problems, the target of the COCOP project is to enable complex industry plants to be operated optimally by the operators with the guidance of a coordinating, real-time optimisation system" [54].
This software solution will be developed, because plantwide optimisation is too complex for a human without the help of a computing tool. The COCOP solution will be a tool giving future users advice how to operate the process more effectively and efficiently. Furthermore, operators will be enabled by improving their understanding and responsibility for the plant-wide production processes, in order to make better decisions in terms of plant-wide results. Therefore, the software solution has to be matched with the practical knowledge and the mental models of operators because many processes are not fully observable and controllable. This is an important challenge of integrating technological and social innovation.

\subsection{The steel case study (Sidenor)}

Sidenor is a steel company with a capacity exceeding one million tons annually, leading in the European steel industry for the production of special steel long products. One of their main producers is forged and cast pieces. It is also an important supplier of cold finished products in the European market. The company has production centres in Basque Country, Cantabria and Catalonia, highly specialised in offering solutions for all industrial sectors requiring high quality steel services: automobile, machinery, capital equipment, naval and civil construction, defense, energy, mining and petrochemical industries. In all of these industries, Sidenor's special steel is used to manufacture reliable products. The company is at the frontline of the sector thanks to their intense research commitment. Having one of the largest Research \& Development (R\&D) centres in the European steel sector, Sidenor's technological developments offer optimisation of products and processes. 


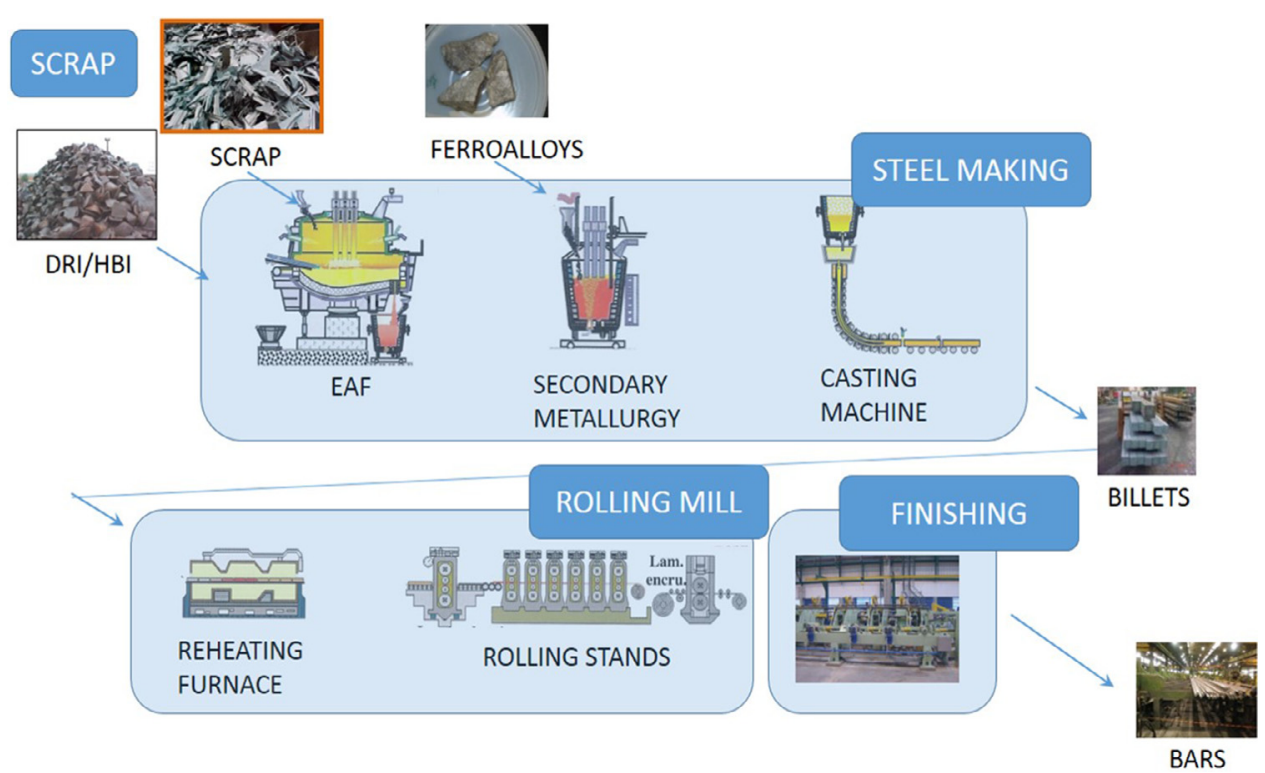

Fig. 3. Flow diagram of the production of Sidenor Basauri Works.

Fig. 3. Organigramme de la production de l'usine Sidenor Basauri.

The COCOP project work focuses on Sidenor Basauri Works. Production facilities at Sidenor Basauri plant include a $140 \mathrm{t}$ electric arc furnace (AC), secondary metallurgy station (two ladle furnaces sharing a vacuum tank degasser) and continuous casting (bloom of $350 \times 470 \mathrm{~mm}$ sq. and billets of 240, 185 and $155 \mathrm{~mm}$ sq. section) process followed by the rolling mill. Figure 3 depicts the production flow of Sidenor Basauri Works.

The steel sector in general is facing a difficult situation due to several factors, such as strong competition from nonEuropean steel producers, high-energy prices and unfavourable environmental regulations. Particularly, the Spanish Special Bar Quality steel sector confronts a situation of loss of competitiveness compared to other countries based on three main reasons: a state energy policy that is unfavourable in view of the intensive character in power consumption of the sector, a restrictive environmental regulation and disadvantageous costs of raw material and human resources. In order to deal with those threats, Sidenor has identified the development and implementation of solutions based on the so-called "Industry 4.0". A series of technologies are already involved in the steel case such as the surface quality measuring techniques, thermographic measurement techniques, data modelling techniques, thermal modelling techniques, data acquisition at different frequencies in SCADAs and PLCs, data storage means like SQL databases and NoSQL databases, data transmission protocols inside Sidenor and outside to other partners. Advanced solutions such as big data and data analysis will be used in the near future for increasing productivity and production volumes at lesser costs. That means, transforming a considered "mature" industry, in a much more competitive nature which is more capable of delivering advanced materials to their customer sectors (characterised by high requirements).
Within COCOP, the steel case study represented by Sidenor is focusing on the superficial quality of microalloyed steel grades. Microalloyed steel grades are a family of steel composition characterised by the effect of alloying small amounts of elements like $\mathrm{V}, \mathrm{Nb}, \mathrm{Ti}, \mathrm{Al}$ combined with $\mathrm{C}$ and/ or N. Those elements form carbonitrides that exert an important effect on the steel properties by controlling the grain size evolution during different stages of the production process. In this way, it is possible to obtain reasonably good properties with simple structures as ferrite/perlite and avoid heat treatments like quenching and tempering. Heat treatments add additional costs to the product, additional energy use and emission generation and steel grades for quenching and tempering need considerable amount of alloys like $\mathrm{Cr}, \mathrm{Ni}$ or Mo that are getting scarcer and more expensive in the last years. Therefore, microalloyed steels are a cheaper and more environmentally friendly substitute to quenching and tempering grades in many applications [55].

Microalloyed steels are a target of great interest in the specialty steel industry due to two reasons:

- there is a growing interest in this steel case as it provides an answer to the aforementioned challenges of increasing competitiveness. Therefore, they form an important and growing percentage of the production in the steel location Basauri;

- the other reason is the low ductility of these steel grades at certain temperatures making them very prone to superficial cracks at the billet surface $[56,57]$.

Therefore, the steel case study is focusing on surface and sub-surface defects of micro-alloyed steels in the asrolled state and how to avoid these defects.

Currently, some steel defects are analysed retrospectively, because there is no sufficiently preventive system that eliminates all defects. To develop such a system, Sidenor is striving to: 
- identify process parameters involved in defect appearance in the three considered processes;

- optimise each sub-process (secondary metallurgy, continuous casting, hot rolling) to avoid defects;

- to apply the decomposition-coordination concept to reach a plant-wide optimisation.

The outcomes will be measured with key performance indicators (KPIs) covering a range of economic, environmental and social indicators, such as productivity in the finishing line, reduction of energy use, $\mathrm{CO}_{2}$ emissions and the economic impact. The social aspects are explicitly measured with social KPI that include indicators for the development process and for the results of the COCOP project. However, relevant information about the social innovation process will be part of the following paragraph.

\section{From software-development to the design of new working practices - findings of empirical research}

\subsection{Methodology}

To perform the development process as a co-creation process that generates not only new technologies but improved working and organisational practices, requirements of future users and (internal) stakeholders of the planned COCOP system have been taken into account, in the COCOP case surveyed by questionnaires and interviews (depicting the starting situation of the innovation process). To do this, COCOP has applied a mixed methodology approach combining quantitative and qualitative research methods. The surveys included the user perspective (operators, installation managers) and the transfer perspective of external experts from different industry sectors. For the steel case, a survey (standardised questionnaires and semi-structured personal or group interviews) was conducted to elaborate the existing situation from the perspective of the future users of the steel pilot case (Sidenor). This investigation will be repeated twice, during the demonstration phase (assessing an initial prototype) and at the final evaluation at the end of the project.

Key performance indicators (KPIs) were developed (using ISO 22400) to monitor and measure the technological, social and process impact of the whole project. E.g., the environmental impact (lower energy usage, decreased $\mathrm{CO}_{2}$ emission) in the steel case will be evaluated by the technical KPI-T1S "Relative Scrap ratio: rejection on the finishing line relative to baseline due to surface quality". The empirical research and measurement of the human factor side is based on social KPIs (see Fig. 4), which are the main reference point for all developed instruments (questionnaires, interviews) and the relevant target groups from a social point of view:

- KPI S1 usage of the system;

- KPI S2 acceptance of system advice;

- KPI S3 plant-wide optimisation (as part of organisational/personnel development, training);

- KPI S4 understanding of plant-wide processes;

\section{Social Dimensions}

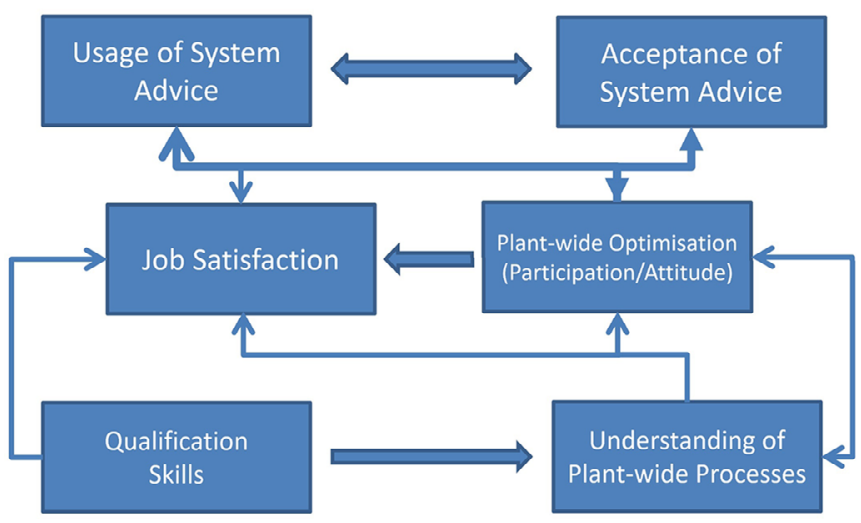

Fig. 4. Social Key Performance Indicators (COCOP).

Fig. 4. Indicateurs clés de performance sociale (COCOP).

- KPI S5 influence on job satisfaction;

- KPI D1 participation, involvement in plant-wide optimisation processes.

These six KPIs reflect the central social dimensions for the system development and implementation from a social perspective. To develop and run the optimisation system, it is of high importance in how far the concerned operators and managers accept and use the new system (operation level). These two KPIs are closely correlated and indicate (as well in an interrelated way) job satisfaction in general and the attitude to and participation of the employees in plant-wide optimisation in general (company level). A third level of KPIs is dedicated to necessary qualifications and skills (education and training level). Skills adjustment is crucial for understanding the plan-wide processes, accepting and using the system (beyond the former narrow perspective of the own production segment). Additionally, it is indirectly leading to higher job satisfaction and the acceptance of plant-wide optimisation processes in general.

The indicators and variables of the developed questionnaire are based on these social KPIs. Responses to the questionnaire were received from future users and company internal stakeholders (steel case) and (as a contrasting perspective) from project external experts of different process industries.

The chosen methodology combines the operating, developing and implementing as well as the transferability perception. Potential users (directly concerned operators/ stakeholders/managers) assessed the COCOP solution for the steel case (Sidenor) - because of the high relevance of this direct and workplace related perspective standardised questionnaires (14 potential users $)^{5}$ and semi-structured interviews in-depth interviews took place (nine potential users). Additionally, sixty external experts from different industry sectors, not involved in the COCOP project, assessed the plant-wide optimisation from their experience

\footnotetext{
5 These 14 interviewees form the basic population of the sample called "future users".
} 
and expertise answering a standardised online questionnaire with the same indicators and variables - contrasting the perspectives of the steel company internal (future) users with external experts' estimations. For both target groups, mainly comparable instruments allow a contrasting analysis by identifying similarities and disparities getting an empirical based comprehensive view on optimisation systems as such and the intended COCOP solution particularly.

\subsection{Results of quantitative research}

As already mentioned, the quantitative (and qualitative) research for the social requirements of COCOP was structured by the social KPIs identified. In the following, a selection of the main important KPI related results of the survey (future users and external experts) is revealed for the steel case, giving the ground for the further operationalisation of social requirements (see Sect. 5):

- job satisfaction, acceptance of plant-wide optimisation as a basic and general acknowledgement of the individual user;

- system usage and acceptance anticipating the former use of the optimisation system;

- skills/training and understanding of plant-wide process as impact and precondition for an optimal usage of the system.

\subsubsection{Relevance of plant-wide optimisation (future users and external experts)}

In general, plant-wide optimisation across all production areas in the plant is accepted and considered to a high degree, for the future users of the company as well as for the external experts. While all the (potential) users agree strongly ( $50 \%$ of the participants) or somewhat $(50 \%)$ to this statement, the also expressed high relevance for the external experts is a bit lower (33\% observe an extreme relevance, see Fig. 5). This underlines a first general result of the surveys: although there is a high positive attitude to plant-wide optimisation and related systems in both groups, the future users do express a higher relevance than the external experts do.

\subsubsection{Impact of plant-wide optimisation on job satisfaction} (future users and external experts)

Overall, former experiences with optimisation systems lead to positive views of the users (see Fig. 6): optimisation systems have increased (strongly or somehow) their possibilities at the workplace $(71 \%)$, made their work more interesting (64\%) and increased their job satisfaction in general $(57 \%)$. The possibilities to reduce the workload are seen differently: $43 \%$ see (strong or somehow) positive effects but $36 \%$ are disagreeing.

Compared with the user perspective, it becomes again evident that the external experts are more critical (lower percentage of "strongly agree") but generally also considering mainly positive impact on job satisfaction for the users. Based on the experiences of the external experts, future

\section{Relevance of Plant-wide Optimisation}

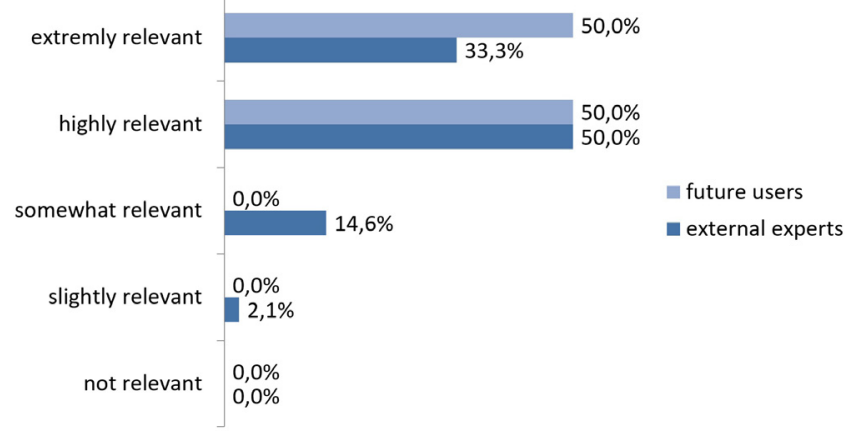

Fig. 5. Relevance of plant-wide optimisation (COCOP).

Fig. 5. Pertinence de l'optimisation à l'échelle de l'usine (COCOP).

optimisation systems will make the work of the concerned operators and managers more interesting, increase their possibilities for decisions at the workplace, reduce their workload and finally increase their job satisfaction. About $60 \%$ of the experts are of this opinion (mainly agreeing somewhat). Nevertheless, there is also a fraction that does not see increasing job satisfaction and possibilities for decisions at the workplace (5-19\%).

\subsubsection{System usage and acceptance (future users) ${ }^{6}$}

Within the questionnaire, participants have also been asked if they have already gained some experiences with existing optimisation systems (currently used software tools, not yet plant-wide optimisation systems). To use these tools is to a high degree a good idea for them, the existing software tools are interesting, useful for the own jobs, recommended by important people (more than half of the participants -50-71\% - strongly agree to these characteristics). The software systems that offer some recommendations for improving processes are seen as a measure to accomplish tasks more quickly and to increase productivity and work performance (50-57\% totally agree).

The high acceptance of plant-wide optimisation and its positive effects on job satisfaction are in line with the positive effects of the anticipated usage of system advices by the (potential) users (see Fig. 7). All of them expect that advice of the existing optimisation systems will make their decisions easier (50\% strongly, $50 \%$ somehow) and the results of the production better $(43 / 50 \%)$. Advice will help users to produce more and better quality, more cost effective and quickly, and reduces the workload (more than half of the users strongly or somewhat agree). The improvement of speediness is a bit more disagreed upon by more than $20 \%$ of the users. Following advices as a habit is seen also positive (14\% strongly and $50 \%$ somewhat

\footnotetext{
${ }^{6}$ To reduce redundancy this chapter reveals only the results of the future users, because the external experts were more or less of the same opinion, but a bit more critical (as already mentioned before).
} 


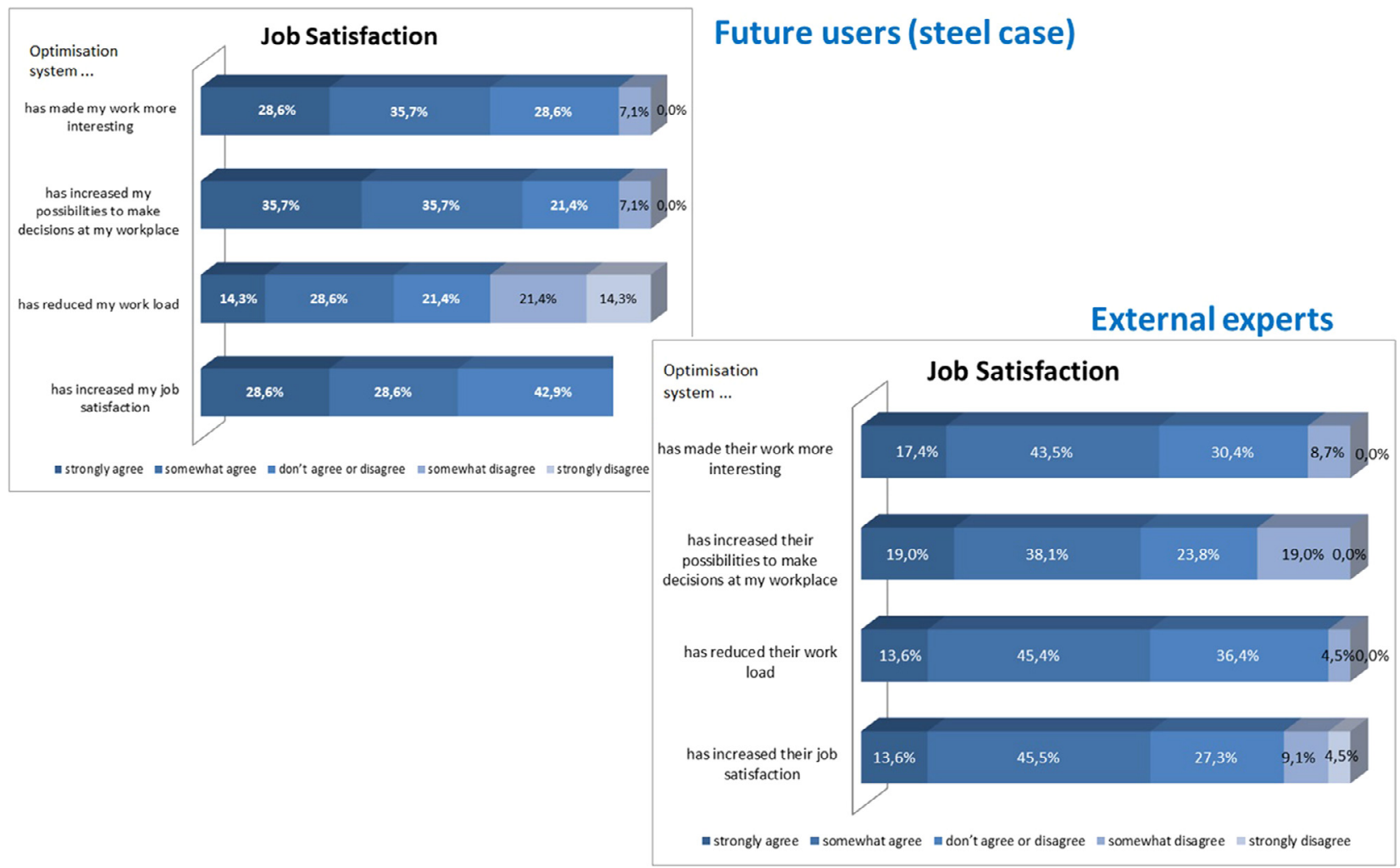

Fig. 6. Influence of optimisation system on job satisfaction (COCOP).

Fig. 6. Influence du système d'optimisation sur la satisfaction au travail (COCOP).

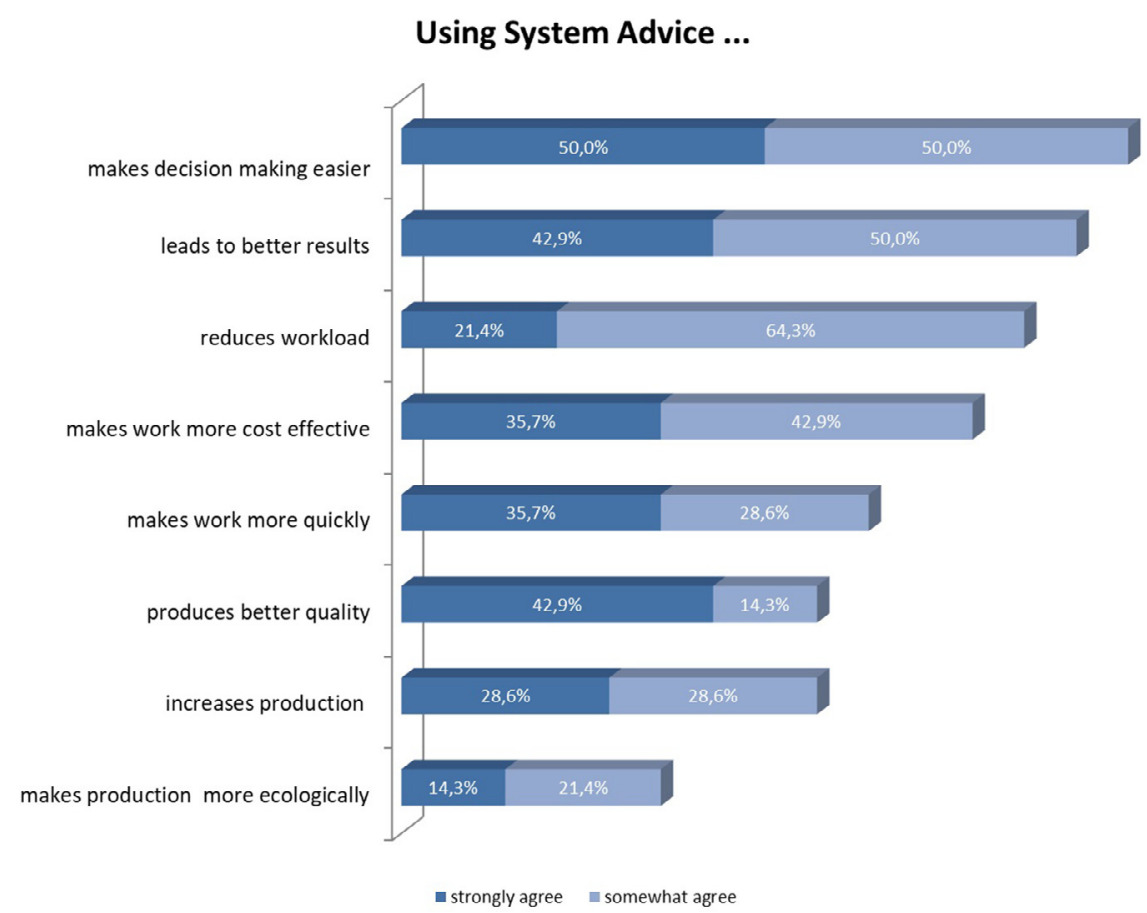

Fig. 7. Usage of advices of the system (future users).

Fig. 7. Utilisation des conseils du système (futurs utilisateurs). 


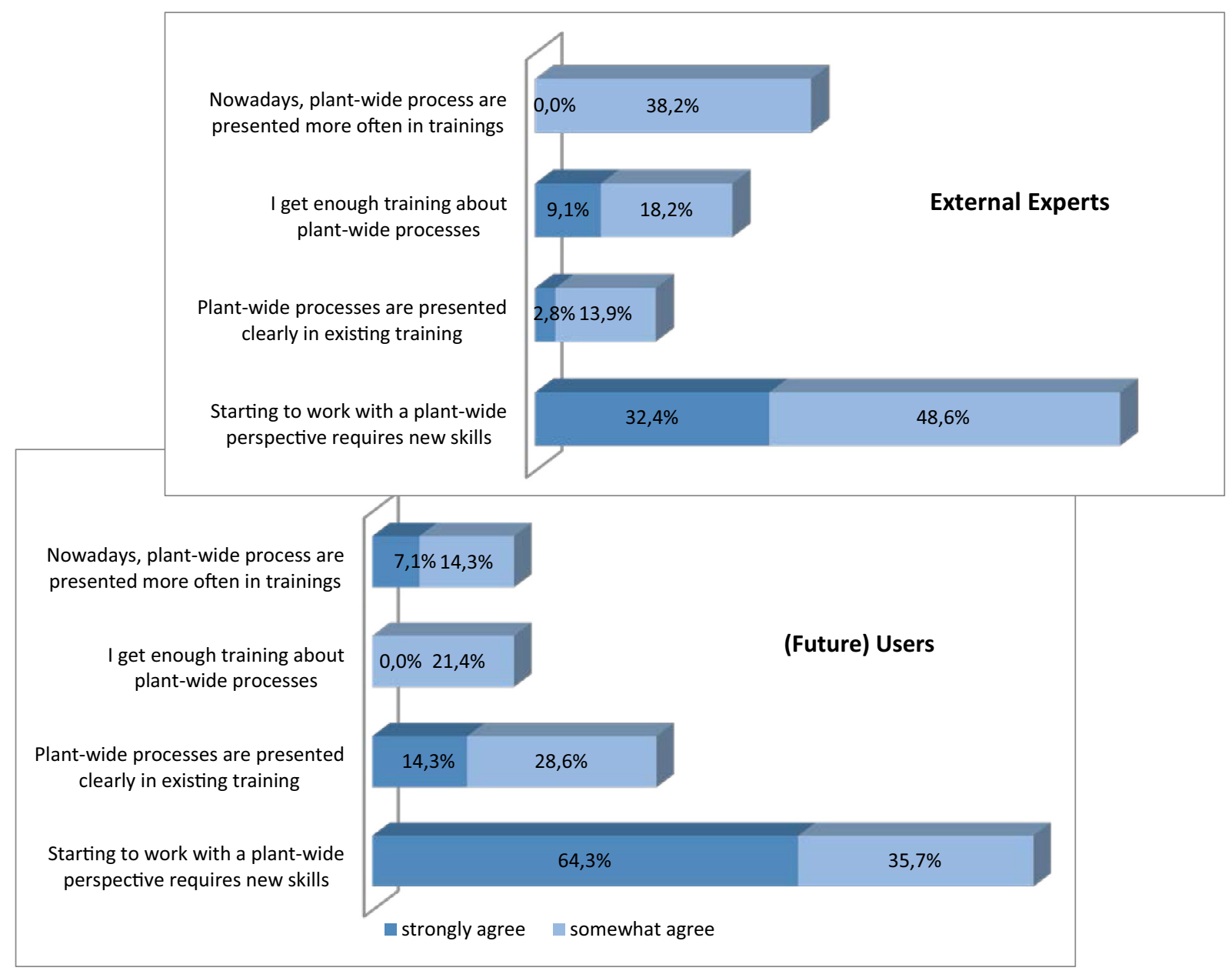

Fig. 8. Skills development (COCOP).

Fig. 8. Développement des compétences (COCOP).

agree, $36 \%$ are unsure). A differentiated view is found in the ecological improvement: $36 \%$ agree and $29 \%$ disagree, the rest is indifferent in its opinion.

However, getting existing systems to do what is intended by the users and the needed mental efforts for interacting with the system are seen differently (about one third and more of half of the participants agree more or less, but there is a higher amount of users who have their difficulties with it). While the majority (57-64\%) find the existing optimisation system at least somehow (not totally) easy to use and the interaction with the system clear and understandable, there are not to be neglected problems of higher amount of users (21-36\% of the participants of the survey).

Currently, the advice provided by the existing software system are followed by a high degree of users (64\%), but no one follows the advices always: $14 \%$ to a middle and $7 \%$ to a low degree, $14 \%$ don't follow them at all. In the future, the optimisation system advice is considered of higher acceptance than today: $7 \%$ of the participants intend to follow them always, $57 \%$ to a high and $36 \%$ to a middle degree (no one mentioned a low degree or not at all). This is in line with an almost very positive picture for the usage of the optimisation system in general in the future: $21 \%$ of the (potential) users consider using the system always, $71 \%$ to a high and $7 \%$ to a middle degree.

\subsubsection{Skills development (future users and external experts)}

This issue concerns necessary skills for using a plant-wide (optimisation) perspective. It includes expectations related to a future optimisation system (such as the COCOP system), but it is not limited only to software but also organisational and work practices.

Starting to work with a plant-wide perspective requires definitely new skills from the perspective of all users (see Fig. 8): about two of three do strongly and one of three somewhat recommend this. Existing training is reflecting this necessity in a lower and differentiated way: only $21 \%$ of the users get enough training or see that plant-wide processes are presented more frequently and clearly in trainings, about $29-50 \%$ disagree somewhat or strongly with these training aspects.

The external experts also underline the necessity of new skills for the plant-wide perspective to a high degree (strongly or somewhat agree to this statement by $81 \%$ ); but again they have a more critical perspective than the users. 


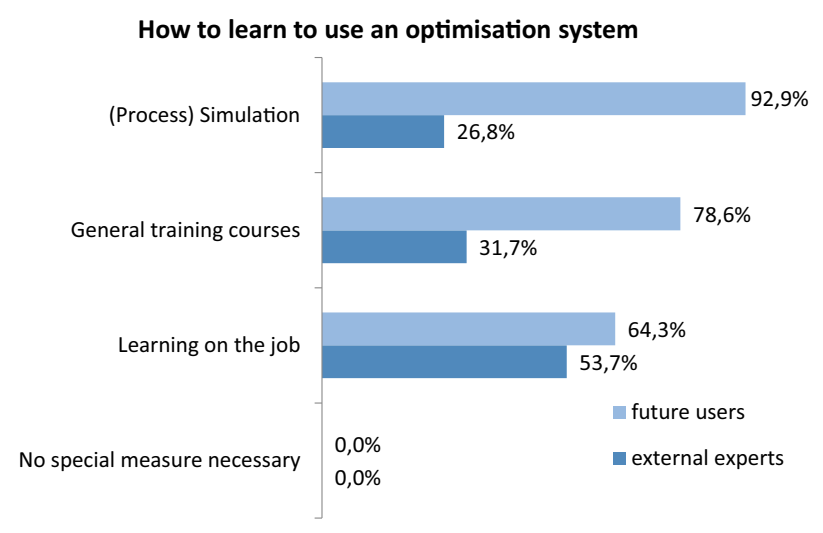

Fig. 9. Expected learning measures (COCOP).

Fig. 9. Mesures d'apprentissage attendues (COCOP).

Based on their experiences, the representation $(38 \%$ strongly or somewhat agree) and especially the sufficient amount $(27 \%)$ and the clear presentation (16\%) of training for plant-wide processes are lacking. Anyway, besides the fact that almost all the experts are recommending the necessity of new skills for plant-wide processes, they show their uncertainty about the status of the training: in general, most of the experts (39-49\%) "don't agree nor disagree".

All the users and external experts stress the necessities of learning measures (see Fig. 9): no one states that no special measures for using an optimisation system are necessary. However, the relevance of specific learning measures is judged in a different way. The users expect that (process) simulation is the favourite learning arrangement for them to require the necessary skills for using new optimisation systems (92\% prefer this measure), also the other measures are of high relevance: general training courses $(79 \%)$ and learning on the job (64\%). While most of the users are favouring a mix of training measures (simulation, courses and learning on the job) the external experts focus on learning on the job (54\%); with less relevance of general training courses $(32 \%)$ and learning through (process) simulation $(27 \%)$.

\subsection{Results of qualitative research}

Additional to the standardised questionnaires, face-to-face or group interviews took place in the beginning of July 2017 at Sidenor in Basauri, Spain. Most of the interviewees were installation managers that will be the main users of a (plant-wide) optimisation system in the steel case. Further interviewees were quality managers and manufacturing technicians (as internal stakeholders). In total, seven interviews with nine people were carried out. Beforehand, these people were identified as key staff that will make use of the future COCOP system. Despite the low number of interview partners, this qualitative research was very important for the project because it provided the requirements of the installation managers and quality supervisors (1) who are very familiar with the production processes, (2) who will mainly use the system and (3) will generate the main benefit of the future COCOP system.
Interview sessions took place in Spanish language with two interviewers (from TU Dortmund University) and representatives of Sidenor and Tecnalia to make sure that technical details were well understood by the interviewers and interviewees. The interviews were recorded and paraphrased before analysed in the present summary.

The interviews gave deeper insights in the current work of future users and in experiences with computer tools supporting optimisation of production processes. Interviews provided qualitative data (details and background information) related to the social KPIs, such as understanding of plant-wide processes, user acceptance of optimisation systems and impacts on job satisfaction. Furthermore, requirements of future users and internal stakeholders were collected according to the elements of a sociotechnical system (technology, organisation, people).

\subsubsection{Central results of the interviews}

The qualitative research is underlining the results of the standardised questionnaire and adding some important context related further information.

For all interviewed people, plant-wide optimisation is of high or extreme relevance for their work. Interviewees show a positive attitude towards advanced optimisation systems. They are anticipating advantages for the production process and for their work by using advanced optimisation systems. They are expecting that COCOP optimisation system will support the users in their original purposes, such as finding solutions for existing problems and optimising processes. Collaboration with upstream and downstream processes is already part of their current job but should be optimised, systemised and more supported.

From the interviews, cross-process analysis is currently seen as a reaction to present problems than a continuous task or information flow. Continuous plant-wide optimisation in the future could benefit in terms of speed and quality of processes. In the interviews, some people are currently missing decisions that are useful for the whole process, not only for single sub-processes. In the present situation, some of the interviewed persons state a lacking software system (like the to-be-developed COCOP solution) that provides data on interrelations between the owned process and previous/subsequent processes.

Some interviewees were explicitly interested in solutions that benefit the whole process not only single subprocesses. They have already gained experience that upstreams processes that have to be taken into consideration to optimise the owned process. The features of a future optimisation system seem to suit the motivating factors of their job (coping with challenges, finding new solutions, optimising processes). Some interviewees could explicitly imagine that the future (COCOP) optimisation system will increase job satisfaction. Positive experiences with existing optimisation systems have generated a high degree of acceptance for future systems. Important for this acceptance conditions are the compatibility with existing systems/tools, the reliability of the system and working with existing standards that enables tracking production results and improving them. 
To accept both existing and future installation of software tools quality, managers need an easy and intuitive usability and a good visualisation of the system. At least, it should make visible the effects of one sub-process on another. One person requested traceability of errors to identify their origin in upstream processes.

Most of the interviewed people stated education and training as a relevant condition for a successful implementation of a (plant-wide) optimisation system. It is important that handling of new software will be learned early on. However, existing trainings are not reflecting this necessity. There is no clear preference for a particular way of learning new skills: (process) simulation, general training courses and learning on the job are all highly relevant from the perspective of most respondents, meaning that a mixture of measures have to be combined. In the interviews, one person stated that not only installation managers should be trained but also operators.

As a result, plant-wide optimisation (not as a software system yet) is already supported by the organisational measures (such as communication and cooperation, incentives and targets, management decisions). However, interviewees stated that more organisational support is needed for the implementation of the future optimisation system. This means improving communication between different production areas (e.g. by common meetings) and providing personal support for the users. One interview partner emphasised explicitly that operators should be involved in optimisation processes correcting wrong decisions.

\section{How could human factors issues really affect the innovation process?}

Based on the results of the quantitative and qualitative surveys, requirements of future users and company internal stakeholders were defined in COCOP called "Human Factors Requirements". These requirements (deriving from the theoretical and empirical analysis) cover all elements of a sociotechnical system: technology, organisation and people. However, since the COCOP project is close to application, some further challenges have to be met to truly influence software development.

A team of human factors experts, KPI experts and software developers ${ }^{7}$ has elaborated on the criteria for describing the human factors requirements to find a common interdisciplinary understanding and to bridge the different "culture" and language of the social and technological perspectives. This is done so that is understandable, helpful and workable for the technical oriented disciplines in the project. Therefore, human factors requirements should be clear, measurable and - in the end - validated, meaning, it can be clearly assessed

\footnotetext{
${ }^{7}$ Many thanks to the members of this team that has substantially contributed to the following content how to define human factors requirements: Toni Lastusilta, Marja Liinasuo, Timo Kuula (VTT, Espoo, Finland) and Roger Ivaska (OPTIMATION, Luleå, Sweden) and Dmitri Domanski (TU Dortmund University, Germany).
}

whether a requirement is fulfilled or not. Answers to interview questions or to questionnaires are usually not formulated as requirements - they are expressed as statements, general descriptions/needs or questions, etc. Therefore, the first step is to translate these answers into requirements that indicate to the members of the development team, how a (sociotechnical) system has to be designed to fulfil the given requirements. The criteria for a clear, measurable and validatable requirement is: Does the (sociotechnical) solution fulfil the human factors requirements - and to what extent? If defined in another, more open manner, technical designers take notice of the users' and stakeholders' needs, but they are not capable to process this information in their further work.

Some of the human requirements could be easily described, e.g. usage of system advice, job satisfaction, etc. However, other requirements cannot be defined sufficiently, as it is not clear in the early stage of a project how they will be manifested in the final (sociotechnical) system. This character of human factors requirements leads to a distinction between result orientated and process orientated requirements. For the result orientated requirements, it can simply be said whether they are fulfilled and to what extent. For instance, whether and how far plant-optimisation is part of operator trainings (e.g. how much time of an operator training will be used for plant-wide optimisation?). However, this data will be available at a late stage in the project timeline, so the (sociotechnical) system is nearly finished and small design scope is remaining to influence system design. To get influence at an early stage of the project, where design scope is considerable, process orientated requirements have to be raised. Although it is difficult to express clear characteristics of these requirements, it can only be assessed whether an appropriate process is in place. For instance, new needed skills to be provided by the personnel development of the company could not be identified in the beginning of the development process. At this time, future users may express their need for additional training, but they do not know which skills they will need and which kind of training might be appropriate to close skill gaps. In such a situation, it can only be considered if a process is in place that covers changes in work content, in the identification of needed new skills, in appropriate trainings to close emerging skill gaps and controlling of education and training measures.

A further distinction has to be made between person-tosystem and person-to-person requirements. The first one could directly be translated in technical requirements specifications, the common form of requirements technical designers are used to consider. Person-to-person requirements are part of the sociotechnical system that will be designed, but not of the new technology itself. The implications of such requirements have to be reflected in the further system development. The Table 1 illustrates some examples for the distinctions made.

Depending on the kind of human factors requirements, they will be treated in a different way. Person-to-system requirements that are related to the final system (e.g. user interface requirements) could be integrated into cases and be defined in project management tools (such as JIRA) familiar to technical designers. The more complex process 
Table 1. Matrix of human factors requirements (filled with examples).

Tableau 1. Matrice des exigences en matière de facteurs humains (remplie d'exemples).

\begin{tabular}{lll}
\hline & Person-to-person requirements & Person-to-system requirements \\
\hline Process-oriented requirements & $\begin{array}{l}\text { It should be estimated if the COCOP } \\
\text { system needs to be supplemented by } \\
\text { further communication channels } \\
\text { (e.g. face-to-face) that are needed } \\
\text { by the (future) users }\end{array}$ & $\begin{array}{l}\text { The COCOP system should be improved } \\
\text { with practical knowledge during the } \\
\text { development, e.g. by excluding non- } \\
\text { realistic solutions }\end{array}$ \\
$\begin{array}{ll}\text { The project should measure plant-wide } \\
\text { processes as part of operator training } \\
\text { ratio relative to baseline }\end{array}$ & $\begin{array}{l}\text { The system should measure } \\
\text { the acceptance ratio of how } \\
\text { often the plant personnel follow } \\
\text { the advice given by the system }\end{array}$ \\
\hline
\end{tabular}

orientated requirements have to be handled differently. They do not describe features of a finished (sociotechnical) system but processes that have to take place to concretise requirements.

\section{Conclusion and outlook}

Based on a new innovation paradigm, an innovation process combining technological and social innovation is being concretised and implemented in the COCOP project generating human factors requirements and enabling their integration within a development process of new digital technologies right from the beginning. As work-in-progress, first research activities revealed the starting point ("baseline") for the intended optimisation system from a human factors perspective:

- process characteristics, key personnel and their tasks, organisational chart of production, current cross-process communication and cooperation and previous attempts of plant-wide optimisation as well are forming the base for the technological development;

- besides technological KPIs, social KPIs were defined in a standardised way (using ISO 22400), understandable for different disciplines: social scientists, software developers, modellers, automation engineers and R\&D departments of companies.

As a central result, it could be stated that there is a good ground for introducing the COCOP system:

- potential users of the COCOP system are ready to take plant-wide or cross-process consequences of their decisions into consideration. The users are very interested in such a system because access to relevant information or procedures of data analysis is currently lacking;

- there are already experiences with existing approaches of plant-wide optimisation. Several potential users have gained already positive experiences with optimisation systems and they are open minded for further developments, knowing already the relevance of upstream processes for the owned process and interested in getting feedback how their decisions/actions affect the final product;
- the features of an optimisation system seem to suit the motivating factors of the job of installation managers in the steel case (coping with challenges, finding new solutions, optimising processes).

Against this backdrop and the more critical perspective of the external experts concerning the recent judgement of the relevant social key performance indicators, the central consequence is that COCOP does not need to create higher acceptance, instead the challenge is not to disappoint the positive attitude and high expectations of the potential users towards the planned optimisation system.

However, there are a few conditions, such as avoiding job losses and additional workload, reliability of the system, user-friendly design, etc. to be fulfilled to improve the system and its acceptance. Some respondents (users and experts) think that it is very difficult to develop a system that is able to optimise the whole process. Therefore, the challenge for COCOP is to show that this is possible and advices of the system are reliable.

Beside the system itself, there are some requirements made for the personnel, organisational and technological framework. Most respondents (users and experts) are expecting new skills that have to be required for using a plant-wide optimisation system. They are not always quite sure how to get acquainted with these new skills, but often they are not satisfied with existing trainings.

In the steel case, respondents stated that current optimisation is already supported by organisational measures, such as management decisions, incentives and targets, etc. Nevertheless, they require additional measures, such as improving cooperation and communication between the different production areas. This seems to be an important precondition to make full use of a plant-wide optimisation system.

Furthermore, respondents called some technological framework conditions to introduce an optimisation system successfully. It should be compatible to the existing systems (such as the Manufacturing Executive System currently used at Sidenor). Users find existing systems at least helpful or even fundamental for their work, not wanting to change it radically, preferring some improvements of the existing system (such as an additional window for advices within the system). 
Table 2. Seven core messages of human factor requirements.

Tableau 2. Sept messages de base sur les exigences en matière de facteurs humains.

Seven core messages

1. COCOP meets the demand of future users, engineers and experts: there is a very high relevance of plant-wide optimisation.

2. It is required by users that the COCOP system will improve their work (contributing to their original purpose, no more complexity and workload).

3. The COCOP system has to be compatible to the existing software systems.

4. The COCOP system has to be user friendly.

5. The COCOP system needs to be embedded in an organisational framework that improves (plant-wide) communication and cooperation.

6. Using the COCOP system will require new skills of the users.

7. (Future) Users and experts are eager to get (or stay) involved in the development of such an optimisation system.

To sum up the results of the basic human factor requirements, seven core messages can be stated (see Tab. 2).

For the ongoing performance of COCOP, the elaborated human baseline prerequisites have to be transformed in clear and measurable requirements that can be validated. Because human factors requirements have to be treated differently in the innovation process, distinctions have to be made between person-to-person and person-to-systems requirements. Technical designers are familiar with personto-systems requirements, but a learning process has to take place to deal with person-to-person requirements that do not cover features of the software system but features of the whole sociotechnical system. Above all, this applies to developing process-orientated requirements that differ from result-orientated requirements (related to the final software system).

Proceeding this way has generated intensive communication processes between technical designers and human factors experts. Thereby, an integrated process of technological and social innovation is really going on.

Based on the experiences with this process, a guideline will be developed on how to define and implement human factors requirements into an integrated technological and social innovation process. This will maintain (or improve) user acceptance, usage ideas of users/stakeholders to be integrated in a holistic way in the (sociotechnical) system taking into account impact on societal, economic and environmental objectives right from the beginning of a project. Expanding this process to a kind of "blueprint" will check the transferability to other process industries (such as copper, chemistry and water treatment) promising substantial benefit by combining technological and social innovation.

\section{References}

1. Organisation for Economic Co-operation and Development OECD, A New Nature of Innovation, Paris, 2009, Available from https://web.archive.org/web/20121126100931/http:// www.newnatureofinnovation.org:80/ [Accessed: 13.11.2018]
2. FORA, New Nature of Innovation, Report to the OECD, Copenhagen, 2009, Available from https://web.archive.org/ web/20160426045708/http://www.tem.fi/files/24835/

New_Nature_of_Innovation.pdf [Accessed: 13.11.2018]

3. The Council of the European Union, Council Decision of 3 December 2013 establishing the specific programme implementing Horizon 2020-the Framework Programme for Research and Innovation (2014-2020) and repealing Decisions 2006/971/EC, 2006/972/EC, 2006/973/EC, 2006/ 974/EC and 2006/975/EC, 2013, Available from https://erc. europa.eu/sites/default/files/document/file/Specific\% 20Programme\%20Horizon\%202020_council_decision_esta blishing_the_specific_programme_implementing_Hori zon_2020.pdf [Accessed: 09.11.2018]

4. Y. Borgmann-Prebil, SI LIVE Opening Session, 2014, Available from https://www.slideshare.net/SIeXchange/silive-opening-session-yuri-borgmannprebil-european-commis sion [Accessed: 09.11.2018]

5. V. Ramaswamy, F.J. Gouillart, The power of co-creation, build it with them to boost growth, productivity and profits, Free Press, New York, 2010

6. SPIRE, SPIRE Vision 2030, 2018, Available from https:// www.spire2030.eu/what/walking-the-spire-roadmap/spirevision [Accessed: 09.11.2018]

7. J. Howaldt, M. Schwarz, Soziale Innovation-Konzepte, Forschungsfelder und-perspektiven, in: J. Howaldt, H. Jacobsen (Eds.), Soziale Innovation, Auf dem Weg zu einem postindustriellen Innovationsparadigma, VS Verlag für Sozialwissenschaften, 2010, pp. 88-108

8. G. Mulgan, Social innovation, the last and next decade, in: J. Howaldt, C. Kaletka, A. Schröder, M. Zirngiebl (Eds.), Atlas of social innovation, new practices for a better future, 2018, pp. 194-197, Available from https://www.socialinnovatio natlas.net/fileadmin/PDF/einzeln/04_Future-Challengesand-Infrastructures/04 01 SI-the-last-and-next-decade Mulgan.pdf [Accessed 09.1̄.2018]

9. European Commission, Social innovation, A decade of changes: a BEPA report, Publications Office of the European Union, 2014, Available from https://espas.secure.europarl. europa.eu/orbis/sites/default/files/generated/document/ en/social_innovation_decade_of_changes.pdf [Accessed $09.11 .201 \overline{8}]$ 
10. J. Howaldt, C. Kaletka, A. Schröder, M. Zirngiebl, Atlas of social innovation-New practices for a better future, TU Dortmund University, Dortmund, 2018

11. V. Colla, A. Schröder, A. Buzzelli, D. Abbà, A. Faes, L. Romaniello, Introduction of symbiotic human-robot-cooperation in the steel sector, an example of social innovation, Matériaux \& Techniques 105, 5 (2017)

12. M. Kohlgrüber, A. Schröder, A new innovation paradigm based on social innovation, 2017, Available from https:// www.cocop-spire.eu/content/new-innovation-paradigmbased-social-innovation [Accessed: 09.11.2018]

13. B. Godin, Innovation contested, The idea of innovation over the centuries, Routledge, London, 2015

14. A. Butzin, J. Howaldt, D. Domanski, C. Kaletka, M. Weber, Innovation Studies, in: J. Howaldt, A. Butzin, D. Domanski, C. Kaletka (Eds.), Theoretical approaches to social innovation, A critical literature review, 2014, pp. 105-121, Available from https://www.si-drive.eu/wp-content/uploads/2014/ 11/D1_1-Critical-Literature-Review.pdf [Accessed: $09.11 . \overline{20} 18]$

15. J. Fagerberg, D.C. Mowery, R.R. Nelson, The Oxford handbook of innovation, Oxford University Press, Oxford, 2005

16. J. Fagerberg, B. Verspagen, Innovation studies, the emerging structure of a new scientific field, Res. Policy 38(2), 218 (2009)

17. J. Howaldt, H. Jacobsen (Eds.), Soziale Innovation, Auf dem Weg zu einem postindustriellen Innovationsparadigma,VS Verlag für Sozialwissenschaften, 2010

18. W. Rammert, Innovation-prozesse, Produkte, Politik, Campus Verlag, 1997

19. W.E. Bijker, T.P. Hughes, T. Pinch (Eds.), The social construction of technological systems, new directions in the sociology and history of technology, MIT Press, Cambridge, Massachusetts, 1987

20. J.A. Schumpeter, Theorie der wirtschaftlichen Entwicklung, Duncker \& Humblot, 1964 [1912]

21. J.A. Schumpeter, Business cycles, a theoretical, historical and statistical analysis of the capitalist process, Vol. 1, McGraw-Hill, New York, Toronto, London, 1939

22. B. Godin, In the shadow of Schumpeter, W. Rupert Maclaurin and the study of technological innovation, Minerva 46(3), 343 (2008)

23. W.R. Maclaurin, Invention and innovation in the radio industry, Macmillan, 1949

24. J. Howaldt, A. Butzin, D. Domanski, C. Kaletka (Eds.), Theoretical approaches to social innovation, a critical literature review, 2014, Available from https://www.sidrive.eu/wp-content/uploads/2014/11/D1_1-Critical-Liter ature-Review.pdf [Accessed: 09.11.2018]

25. J. Schot, W.E. Steinmueller, Three frames for innovation policy, R\&D, systems of innovation and transformative change, Res. Policy 47(9), 1554 (2018)

26. C. Freeman, Technology policy and economic performance, lessons from Japan, Pinter, London, New York, 1987

27. C. Freeman, C. Perez, Structural crisis of adjustment, business cycles and investment behaviour, in: G. Dosi, C. Freeman, R. Nelson, G. Silverberg, L.L. Soete (Eds.), Technical change and economic theory, Pinter, London, 1988, pp. 38-66
28. S. Metcalfe, The economic foundations of technology policy, equilibrium and evolutionary perspectives, in: P. Stoneman (Ed.), Handbook of the economics of innovation and technical change, Blackwell, Oxford, 1995, pp. 409-512

29. Bureau of European Policy Advisers, European Commission, Empowering people, driving change, Social innovation in the European Union, Publications Office of the European Union, 2010

30. P. Brödner, Options for CIM, "unmanned factory" versus skill-based manufacturing, Comput. Integr. Manufactur. Syst. 1(2), 67 (1988)

31. J. Howaldt, R. Kopp, J. Schultze, Why industry 4.0 needs workplace innovation, a critical essay about the German debate on advanced manufacturing, in: P.R.A. Oeij, D. Rus, F.D. Pot (Eds.), Workplace innovation, theory, research and practice, Springer, Cham, 2017, pp. 45-60

32. E.L. Trist, K.W. Bamforth, Some social and psychological consequences of the longwall method of coal-getting, an examination of the psychological situation and defences of a work group in relation to the social structure and technological content of the work system, Hum. Relat. 4 (1), 3 (1951)

33. B. Lutz, Das Ende des Technikdeterminismus und die Folgen, Soziologische Technikforschung vor neuen Aufgaben und Problemen, in: B. Lutz (Ed.), Technik und sozialer Wandel, Verhandlungen des 23. Deutschen Soziologentages in Hamburg 1986, Campus Verlag, Frankfurt, 1987, pp. $34-52$

34. F.D. Pot, P. Totterdill, S. Dhondt, The need to uncover the field of workplace innovation, in: P.R.A. Oeij, D. Rus, F.D. Pot (Eds.), Workplace innovation, theory, research and practice, Springer, 2017

35. P.T. Bolwijn, J. Boorsma, Q.H. van Breukelen, S. Brinkman, T. Kumpe, Flexible manufacturing, integrating technological and social innovation, Elsevier Science Ltd, Amsterdam, 1986

36. C.A. Gardner, T. Acharya, D. Yach, Technological and social innovation, a unifying new paradigm for global health, Health Aff. 26(4), 1052 (2007)

37. K. Green, P. Vergragt, Towards sustainable households, a methodology for developing sustainable technological and social innovations, Futures 34, 381 (2002)

38. R.P. van der Have, L. Rubalcaba, Social innovation research, An emerging area of innovation studies? Res. Policy 45(9), 1923 (2016)

39. J. Howaldt, M. Schwarz, Social innovation, concepts, research fields and international trends, Dortmund, 2010, Available from http://www.sfs.tu-dortmund.de/odb/Repository/Publi cation/Doc/1289/IMO Trendstudie Howaldt Schwar

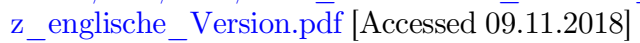

40. H. Brooks, Social and technical innovation, in: S.B. Lundstedt, E.W. Coldglazier, Jr. (Eds.), Managing innovation, Pergamon Press, New York, 1982

41. S. Dhondt, P. Oeij, Social innovation related to innovation in management studies, in: J. Howaldt, A. Butzin, J. Howaldt, D. Domanski, C. Kaletka (Eds.), Theoretical approaches to social innovation, A critical literature review, Dortmund, 2014, pp. 122-150, Available from https://www.si-drive.eu/ wp-content/uploads/2014/11/D1_1-Critical-Literature-Re view.pdf [ Accessed 09.11.2018] 
42. J. Womack, D. Jones, D. Ross, The machine that changed the world, the story of lean production, Free Press, New York, 1990

43. H. Chesbrough, M. Bogers, Explicating open innovation, clarifying an emerging paradigm for understanding innovation, in: H. Chesbrough, W. Vanhaverbeke, J. West (Eds.), New frontiers in open innovation, Oxford University Press, 2014, pp. 3-28

44. H.W. Chesbrough, Open innovation, the new imperative for creating and profiting from technology, Harvard Business School, 2003

45. H. Chesbrough, W. Vanhaverbeke, J. West (Eds.), Open innovation, researching a new paradigm, Oxford University Press, 2008

46. E. Shove, M. Pantzar, M. Watson, The dynamics of social practice, everyday life and how it changes, SAGE Publications, London, 2012

47. K. Schwab, Die vierte Industrielle Revolution, Pantheon, 2016

48. H.J. Hirsch-Kreinsen, Digitization of industrial work, development paths and prospects, J. Labour Mark. Res. 49(1), 1 (2016)

49. J. Dregger, J. Niehaus, P. Ittermann, H. Hirsch-Kreinsen, M. ten Hompel, The digitization of manufacturing and its societal challenges, a framework for the future of industrial labor, 2016 IEEE International Symposium on Ethics in Engineering, Science and Technology, 2016, pp. 1-3
50. A.-W. Scheer, CIM Computer Integrated Manufacturing, Der computergesteuerte Industriebetrieb, Springer, 1990

51. J.-B. Waldner, Principles of computer-integrated manufacturing, John Wiley \& Sons, Chichester, United Kingdom, 1992

52. M. Ten Hompel, M. Putz, A. Nettsträter, The social networked industry, white paper, fraunhofer, n.y., Available from https://www.e3-produktion.de/content/dam/iwu/e3produktion/de/documents/E3_Whitepaper_SocialNetwor kedIndustry_Web.pdf [Accessed: 09.11.2018]

53. R. Kopp, S. Dhondt, H. Hirsch-Kreinsen, M. Kohlgrüber, Positioning workplace innovation from different sociotechnical perspectives on logistics and process industries, Int. J. Technol. Transf. Commer., Forthcoming 2018

54. M. Villko, Efficient plant operation, a plant-wide approach, 2017, Available from https://www.cocop-spire.eu/content/ efficient-plant-operation- $\% \mathrm{E} 2 \% 80 \% 93$-plant-wide-approach

55. J.R. Davis, "High-strength low-alloy steels", Alloying: Understanding the basics, ASM International, Ohio, 2001

56. S. Riaz, G. Alvarez de Toledo, A. Arteaga, J. Komenda, S. Zamberger, N. Triolet, E. Erdem, Behaviour of microalloyed steels during solidification and cooling (precipitation), RFSR-CT-2005-00014, European Commission, 2010

57. G. Alvarez de Toledo, J. Komenda, T. Brune, S. Münch, B. Stewart, Influence of composition and continuous casting parameters on the precipitation of microalloyed particles of B microalloyed steel grades and Mn alloyed steel grades (PMAP), European Commission, 2018

Cite this article as: Michael Kohlgrüber, Antonius Schröder, Félix Bayón Yusta, Asier Arteaga Ayarza, A new innovation paradigm: combining technological and social innovation, Matériaux \& Techniques 107, 107 (2018) 